\title{
Análises de açúcares e ácidos clorogênicos de cafés colhidos em diferentes estádios de maturação e após o processamento
}

\author{
Analysis of sugars and chlorogenic acid in coffee harvested at different ripening stages \\ and after processing
}

\author{
Rogéria Assis dos Santos ${ }^{1}$, Marcelo Alexandre Prado', Rosa Elena Pertierra², Héctor Abel Palacios ${ }^{2,3 *}$ (i) \\ 1 Universidade Estadual de Campinas (UNICAMP), Faculdade de Engenharia de Alimentos, Campinas/SP - Brasil \\ 2 Universidad Estatal Península de Santa Elena, Facultad de Ciencias Agrarias, Santa Elena - Ecuador \\ ${ }^{3}$ Universidad de Las Americas (UDLA), Facultad de Engenharia Agroindustrial, Quito - Ecuador
}

\section{*Corresponding Author}

Héctor Abel Palacios, Universidad de Las Americas (UDLA), Facultad de Engenharia Agroindustrial, Calle José Queri, s/n, Avenida José Granados Campus Queri, Quito - Ecuador, e-mail: hector.palacios@udla.edu.ec

Cite as: Analysis of sugars and chlorogenic acid in coffee harvested at different ripening stages and after processing. Braz. J. Food Technol., v. 21, e2017163, 2018

Received: Mar. 20, 2017; Accepted: June 11, 2018

\section{Resumo}

Componentes como açúcares e ácidos clorogênicos, que são acumulados durante a maturação dos grãos de café, possuem importante papel na qualidade da bebidanão somente atribuído a sua alta concentração, mas também às alterações ocorridas nos grãos durante a torração. Os açúcares predominantes nos grãos de café são frutose, glicose e sacarose. Porém, os ácidos clorogênicos podem ser responsáveis pela desvalorização na qualidade da bebida, devido à intensa degradação térmica durante o processamento dos grãos. Este estudo teve como objetivo avaliar a composição química destas duas substâncias durante as etapas pós-colheita em cafés colhidos em diferentes estádios de maturação, pela técnica de Cromatografia Liquída de Alta Eficiência (CLAE). Com relação aos monoisômeros dos ácidos clorogênicos, o teor de 5-acido cafeoilquinico (5-CQA) teve aumento durante o processamento dos grãos, apesar de ter se mantido instável durante as etapas de secagem em terreiro. Os três lotes estudados foram: Lote 1, representado por $90 \%$ frutos cereja $+10 \%$ frutoscru; Lote 2 , frutos $100 \%$ cereja; e Lote 3, $85 \%$ frutos boia $+10 \%$ frutos cereja $+5 \%$ frutos cru. Esses lotes diferiram significativamente entre si com relação ao teor de 5-CQA. Com referência ao lote 2, este foi o lote que apresentou a maior concentração de 5-CQA, por outro lado, durante o processo de torração e elaboração da bebida, ocorreu redução no teor de 5-CQA. Os teores dos isômeros 3 e 4 não apresentaram uma tendência definida de aumento ou diminuição durante o processamento. Com relação aos açúcares, uma maior concentração de sacarose foi encontrada no lote 3 . Ainda vale ressaltar que o teor de sacarose teve um aumento durante o processamento, enquanto os teores de frutose e glicose teve uma diminuição. Após a torração, os níveis de sacarose, frutose e glicose diminuíram significativamente, e não houvedetectação tanto de glicose quanto de frutose nos grãos torrados. O método escolhido para a determinação dos açúcares e ácidos clorogênicos foi considerado eficiente diante dos resultados obtidos durante a validação dos métodos.

Palavras-chave: Coffea arabica L.; Cromatografia líquida de alta eficiência; Ácido cafeoilquínico; 5-CQA; Sacarose; Açúcares redutores; Café torrado.

\section{Abstract}

Compounds such as sugar and clorogenic acids, accumulated during the ripening of coffee beans, have an important role in beverage quality, which is ascribed not only to their high concentration, but also to the changes occurring during roasting. The predominant sugars present in coffee beans are glucose, fructose and sucrose. Chlorogenic acids may be responsible for a loss in beverage quality, since they suffer intense thermal degradation during bean processing. The objective of this study was to evaluate the behaviour of the chemical compounds during the post-harvest steps in coffees harvested at different ripening stages, using High Performance Liquid Chromatography (HPLC). With respect to the 
chlorogenic acid monoisomers, the 5-CQA content tended to increase during the bean processing, despite being unstable during sun drying. The three batches studied (batch 1: $90 \%$ cherry $+10 \%$ unripe; batch 2: $100 \%$ cherry; batch $385 \%$ floaters $+10 \%$ cherry $+5 \%$ unripe) presented significantly different 5-CQA contents, batch 2 presenting the highest concentration. During the roasting process and elaboration of the beverage, a reduction in the 5-CQA contents occurred. The levels of the isomers 3 and 4 showed no defined tendency to increase or decrease during processing. With respect to the sugars, the sucrose content tended to increase and the fructose and glucose contents decreas during processing. A higher concentration of sucrose was found in batch 3. After roasting, the levels of sucrose, fructose and glucose decreased drastically, glucose and fructose not being detected in the roasted beans. The method chosen to determine the sugar and clorogenic acid contents was considered efficient during validation of the methods, due to the results obtained.

Keywords: Coffea arabica L.; High performance liquid chromatography; Caffeoylquinic acid; 5-CQA; Sucrose; Reducing sugars; Roasted coffee.

\section{Introdução}

Os açúcares estão diretamente ligados à qualidade do café, contribuindo com o seu sabor adocicado, uma das características mais desejáveis no café gourmet. Ainda discute-se sobre qual deve ser o tipo e a concentração de açúcares nos grãos, e também de como essa concentração exerceria maior influência nos atributos de qualidade da bebida, tais como: sabor, amargor, cor, acidez e aroma. De fato, existe uma relação positiva entre a qualidade do café e a quantidade de açúcares redutores e não redutores, ao passo que maiores concentrações de açúcares no grão cru permitem um aumento desses componentes nas reações do processo de torração. Substâncias voláteis, principalmente furanos, são formadas com a combinação de açúcares e proteínas, que são responsáveis, em grande parte, pelo aroma do café (PUERTA, 2011; ARRUDA et al., 2012).

Com relação aos açúcares livres dominantes nos grãos de café, esses são basicamente frutose, glicose e sacarose; porém, também podem ser encontrados traços de outros açúcares, como estaquiose, rafinose, arabinose, manosee galactose (ILLY; VIANI, 1998). A sacarose é o açúcar de baixo peso molecular de maior abundância no café, e seu teor pode variar de 3 a $7 \%$, e de 6 a $9 \%$ em base seca, principalmente em grãos das espécies robusta e arábica, respectivamente (PUERTA, 2011).

Entretanto, os componentes fenólicos encontram-se amplamente distribuídos no reino vegetal, e compreendem um grupo heterogêneo de substâncias, apresentando tanto estruturas químicas relativamente simples quanto estruturas complexas, como taninos e ligninas. Nos frutos de café, existe um alto teor de componentes fenólicos, em particular o ácido clorogênico (VIGNOLI et al., 2011). Segundo Tavares e Ferreira (2006), Redgwell e Fischer (2006) e Perrone et al. (2008), os ácidos clorogênicos sofrem intensa degradação térmica durante o processamento do grão, originando uma série de componentes voláteis de baixo peso molecular e, os mesmos apresentam características sensoriais bem variadas, isto é, odores de matéria queimada, especiarias, cravo, fumo, e também sensação de amargor e adstringência (TOCl et al., 2006).
Os componentes fenólicos do café, principalmente os ácidos caféico e clorogênicos, exercem ação protetora e antioxidante sobre os aldeídos. Portanto, em virtude de qualquer condição adversa dos grãos, ou seja, colheita inadequada, problemas no processamento e armazenamento, faz com que as polifenoloxidases terminem por agir sobre os polifenóis, diminuindo suas açõesão antioxidantes nos aldeídos, deste modo facilitando a oxidação e interferindo no sabor e aroma do café após a torração (CLIFFORD, 1999).

Segundo Vignoli et al. (2011), as perdas de ácidos clorogênicos (ACGs) entre as torrações suave e forte estão em uma média de $86 \%$ para arábica, e de 93\% para robusta. Os ACGs são facilmente solubilizados em água quente; portanto, os mesmos estarão presentes na bebida, tendo em vista que o café é uma das principais fontes de ACGs na dieta humana. Como exemplo, uma xícara da bebida ( $200 \mathrm{~mL}$ ) pode conter cerca de 20-675 mg de ACGs, dependendo da espécie de café e das condições de processamento (MARIA; MOREIRA, 2004).

Apesar de existir muitos trabalhos na literatura que quantifiquem carboidratos e ácidos clorogênicos totais em café, ainda há poucos estudos que realizam a quantificação de açúcares e ácidos clorogênicos individuais. Embora existam várias técnicas de identificação dos componentes totais ou individuais presentes em café, Chirinos et al. (2008) indicaram a técnica de CLAE, pois a mesma apresenta vantagem porser um método versátil e preciso.

Logo, tanto os açúcares de maior relevância em café (sacarose, frutose e glicose) quanto o ácido cafeoilquínico (CQA) e seus isômeros 3, 4 e 5, são muito importantes como precursores de aromas e sabores que conferem boa qualidade ao café. Não há trabalhos científicos que tenham reportado o efeito do tempo de colheita sobre as concentrações de açúcares e ACGs. Neste estudo, avaliou-se o efeito da colheita do café em diferentes estádios de maturação, assim como o processamento pós-colheita sobre a composição dos açúcares e ACGs. 
Análises de açúcares e ácidos clorogênicos de cafés colhidos em diferentes estádios de maturação e após o processamento Santos, R. A. et al.

\section{Materiais e métodos}

\subsection{Matéria-prima e processamento}

Para análise dos ácidos clorogênicos, foram analisados três lotes de café arábica da cultivar Mundo Novo, que foram monitorados durante a pós-colheita, e posteriormente colhidos em diferentes estádios de maturação.

Para o processamento pós-colheita do café, o procedimento foi dividido em etapas que foram descritas na Tabela 1. As etapas L1 e L2 (que representaram a primeira época do estudo) foram similares, com o lote 2 representado por $100 \%$ café cereja, e o lote 1 , $90 \%$ café cereja e 10\% café cru. Em contrapartida, o lote $3(85 \%$ café boia $+10 \%$ café cereja $+5 \%$ café cru) representou a segunda época do estudo, com café colhido 45 dias após a colheita da primeira época. Essa época representou o café que permaneceu maior parte do tempo de secagem na árvore, portanto precisou de menor tempo no terreiro para secagem. Sendo assim, não existiu a etapa "Terreiro 4" na segunda época do estudo (ver Tabela 1).

\subsection{Amostragem}

Foi selecionado um talhão para cada época. Com relação à época 1, que correspondeu aos lotes L1 e L2, foram colhidos aproximadamente $30.000 \mathrm{~kg}$ de café que foi seco em terreiros de cimento. Em seguida, o café foi colocado no terreiro em um trator de capacidade de $3.000 \mathrm{~kg}$ de produto. Em cada viagem, durante o esvaziamento de aproximadamente três minutos, foi colhida uma amostra de produto (aproximadamente $10 \mathrm{~kg}$ ), e o mesmo foi colocado no terreiro de forma separada. Para o lote L2, foram amostrados somente grãos cerejas (100\%), e com referência à amostragem de produto na segunda época (L3), a mesma metodologia foi realizada para a época 1.

\subsection{Preparação da amostra antes da extração dos ácidos clorogênicos e açúcares}

As amostras denominadas como cru, assim como dos grãos crus, incluíram os frutos amostrados durante a secagem dos mesmos em terreiro. Depois de coletados, os frutos foram imediatamente congelados até o momento da análise, e os grãos em coco, referentes às etapas pós-secagem em terreiro, foram primeiramente beneficiados e posteriormente congelados. A preparação das amostras em laboratório foi ilustrada conforme a Figura1:

As três amostras de café dos lotes $(1,2,3)$ de café arábica referentes às análises em grãos torrados foram torradas separadamente durante 15 minutos a $218^{\circ} \mathrm{C}$ em um torrador de tambor rotativo, elétrico, adequado para laboratório, da marca Pinhalense modelo TP.2, com

Tabela 1. Etapas do processamento pós-colheita do café. Lote 1 (frutos $90 \%$ cereja + frutos 10\%cru); Lote 2 (frutos 100\% cereja); Lote 3 (frutos $85 \%$ café boia + frutos $10 \%$ cereja + frutos $5 \% \mathrm{cru}$ ).

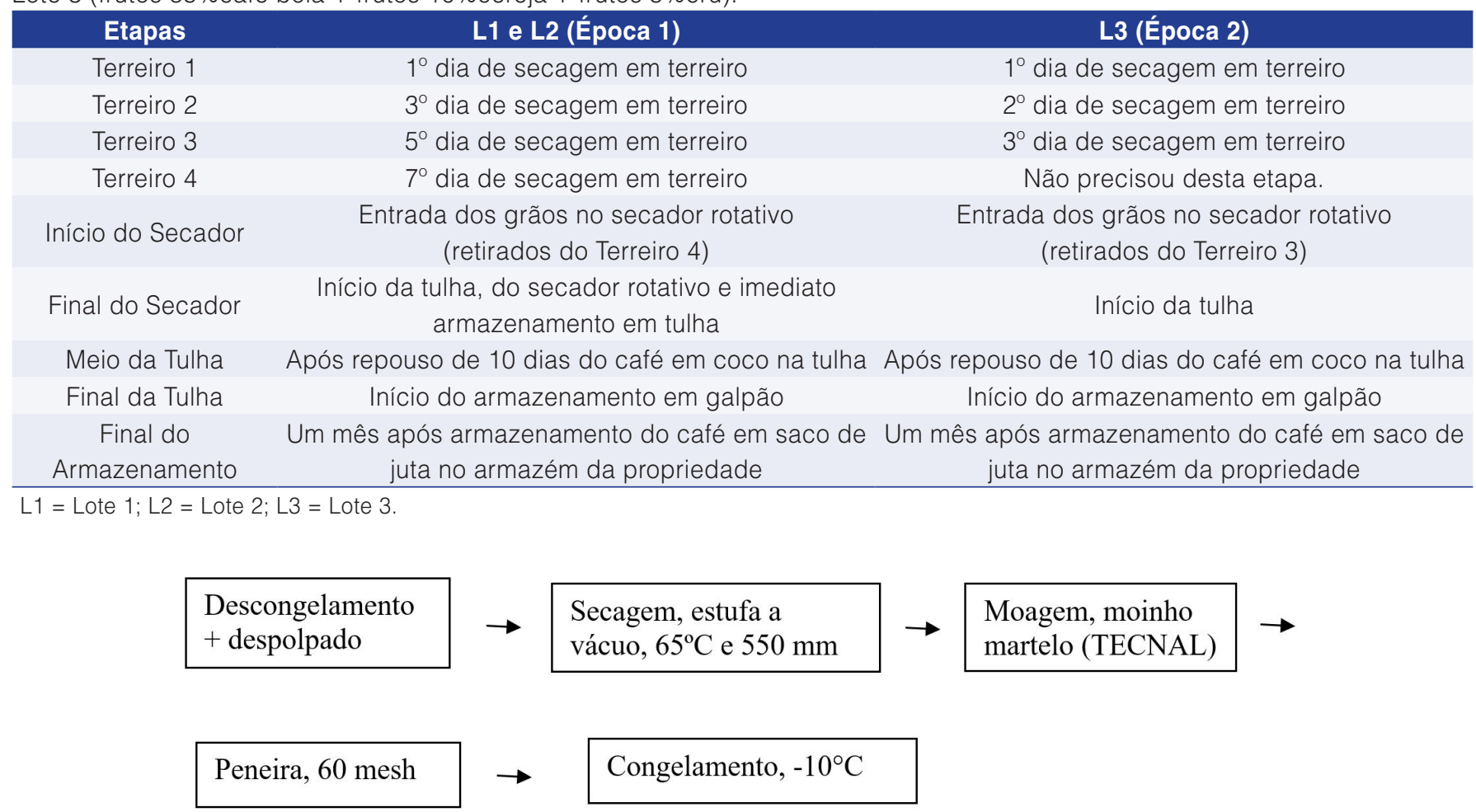

Figura 1. Fluxo de etapas antes da extração dos ácidos clorogênicos e açúcares. 
Análises de açúcares e ácidos clorogênicos de cafés colhidos em diferentes estádios de maturação e após o processamento Santos, R. A. et al.

capacidade de $200 \mathrm{~g}$ por tambor. Todas as amostras torradas foram classificadas pelo sistema Agtron/SCAA "Roast Classification color disk" como torra clara. Após a torração, os cafés foram moídos e peneirados (peneira de 60 mesh).

As bebidas foram preparadas em filtro de papel, à proporção de $8 \mathrm{~g}$ de café torrado e moído para $100 \mathrm{~mL}$ de água, a aproximadamente $98^{\circ} \mathrm{C}$.

\subsection{Extração dos ácidos clorogênicos de cafés crus e torrados}

A 500 mg de amostras de cafés moídos (cru ou torrado) foram adicionados aproximadamente $80 \mathrm{~mL}$ de água deionizada a $80^{\circ} \mathrm{C}$. Agitou-se a mistura por 15 minutos a 300 rpm, e então adicionaram-se $2 \mathrm{~mL}$ da solução de Carrez (1 mL de cada solução) para precipitação do material coloidal. O volume foi completado a $100 \mathrm{~mL}$ com água deionizada, e colocou-se a mistura em repouso por 10 minutos, e a mesma foi posteriormente filtrada em papel qualitativo Whatman 1.

\subsection{Extração dos ácidos clorogênicos da bebida de café}

As bebidas foram preparadas em filtro de papel aproximadamente a $98^{\circ} \mathrm{C}$, à proporção de $8 \mathrm{~g}$ de café torrado e moído para $100 \mathrm{~mL}$ de água deionizada. Em seguida, foram pipetados $20 \mathrm{~mL}$ da bebida e adicionados $1 \mathrm{~mL}$ de cada reagente de Carrez, sendo que posteriormente o volume foi ajustado a $100 \mathrm{~mL}$ com água deionizada e, após 10 minutos de repouso, a mistura foi filtrada em papel Whatman 1. Antes de cada injeção no equipamento, todos os extratos foram filtrados em filtro Milipore HATF 0,45 $\mu$ m, e cada extrato foi injetado em triplicada no cromatógrafo.

\subsection{Extração dos açúcares de café cru e torrado}

Foram adicionados aproximadamente $25 \mathrm{~mL}$ de água deionizada a $80^{\circ} \mathrm{C}$ em $2 \mathrm{~g}$ de amostras moídas (cru e torrada) que foram levadas ao banho-maria a $80^{\circ} \mathrm{C}$ com agitação de 150 rpm por 45 minutos. Após o esfriamento, foram adicionados $2 \mathrm{~mL}$ de creme de alumina em um balão, e o volume foi completado a $50 \mathrm{~mL}$ com água deionizada. Em seguida a solução foi agitada, permanecendo em repouso por 10 minutos, e por fim filtrada em papel qualitativo Whatman 1. Após essa filtração, pipetou-se uma alíquota de 1,5 mL do extrato para um balão volumétrico calibrado de $5 \mathrm{~mL}$, e o volume foi completado com acetonitrila grau PA.

Antes de cada injeção no equipamento, todos os extratos foram filtrados em filtro Milipore HATF 0,45 $\mu \mathrm{m}$, e injetou-se cada extrato em triplicata no cromatógrafo.

\subsection{Identificação e quantificação dos açúcares}

A separação dos picos dos açúcares ocorreu em CLAE, utilizando-se coluna Merck-Lichrospher $\left(100 \mathrm{NH}_{2}, 5 \mu \mathrm{m}, 250 \times 4 \mathrm{~mm}\right)$, em um cromatógrafo Shimadzu, composto de bomba quaternária, injetor automático, sistema de desgaseificação por membrana, assim como forno, controladora, um detector de índice de refração com "loop" de $20 \mu \mathrm{L}$, e o software CLASS-VP. Para a fase móvel, utilizou-se acetonitrila grau HPLC e água $(80: 20 \mathrm{v} / \mathrm{v})$ com fluxo de $1,0 \mathrm{~mL} / \mathrm{min}$, conforme Toci et al. (2006). Os padrões utilizados foram os mesmos para sacarose, frutose e glicose da marca Sigma. Para a identificação e quantificação dos açúcares, foi injetado um pool dos três padrões com concentrações conhecidas.

\subsection{Identificação e quantificação dos ácidos clorogênicos e de seus isômeros}

A separação ocorreu em CLAE-DAD e utilizou-se uma coluna de fase reversa Merck-Lichrospher (100, 5 m, $250 \times 4$ mm), em um cromatógrafo Shimadzu 10 A-VP, composto de bomba binária, injetor automático, sistema de desgaseificação por membrana, forno, controladora e um detector de arranjo de diodo DAD-M10A-VP em $\lambda$ máx de 325 nm, e por fim o software utilizado foi o CLASS-VP. As fases móveis utilizadas foram: metanol grau CLAE (FMA), solução tampão de ácido cítrico com modificador TBA a 0,01 molar (FMB) e pH 2,5, com fluxo de 1,0 mL/min obedecendo a programação de gradiente. O padrão utilizado foi o ácido 5-cafeoilquínico (5-CQA), Clorogenic Acid da marca Sigma. Para identificar os isômeros 3-CQA e 4-CQA, o padrão 5-CQA foi submetido à isomerização pela metodologia citada por Trugo e Macrae (1984).

\subsection{Validação de metodologias}

\subsubsection{Validação de método do ácido clorogênico (5-CQA)}

Para esta validação, o método utilizado, tanto para a identificação quanto para a quantificação de ACGs e açúcares por CLAE, foi avaliado com relação à linearidade, recuperação do analito, limites de detecção (LMD), quantificação do equipamento (LMQ) e dos métodos. A linearidade foi estabelecida com dez concentrações no intervalo de 0,2 a $50 \mu \mathrm{g} / \mathrm{mL}$, e a recuperação do analito foi avaliada em três concentrações de 2,5, 5 e $10 \mu \mathrm{g} / \mathrm{mL}$, ao passo que o limite de detecção e quantificação do equipamento foi realizado segundo Quatrocchi et al. (1992). Com base nos limites de detecção e quantificação dos métodos em ug, os mesmos foram calculados considerando-se a porcentagem de recuperação da amostra adicionada, uma vez que esta amostra diferiu de 100\%. 
Análises de açúcares e ácidos clorogênicos de cafés colhidos em diferentes estádios de maturação e após o processamento Santos, R. A. et al.

\subsubsection{Validação de métodos dos açúcares redutores e da sacarose}

Para a validação dos métodos, foram utilizados os mesmos parâmetros para a validação de ACSs. A linearidade foi estabelecida com onze concentrações que abrangeram a faixa de 0,25 a $30 \mu \mathrm{g}$ em $20 \mu \mathrm{L}$. Para a recuperação do analito, esta validação foi avaliada em sete diferentes concentrações: 0,25, 2, 2,5, 5, 10, 15 e $20 \mu \mathrm{g}$ nos $20 \mu \mathrm{L}$ injetados. Os limites de detecção e quantificação do equipamento foram determinados segundo Quatrocchi et al. (1992), em que foram injetados um pool de padrões nas concentrações de 0,10, 0,15 e 0,20 $\mu \mathrm{g}$ nos $20 \mu \mathrm{L}$ injetados. Logo,os limites de detecção e quantificação dos métodos foram calculados de forma similar aos ACSs.

\section{Resultados e discussão}

Os resultados da validação dos métodos para identificação e quantificação dos açúcares e ACSs utilizando CLAE foram descritos na Tabela 2.

\section{1 Ácidos clorogênicos totais}

No presente trabalho, avaliou-se o grupo de maior relevância dos ácidos clorogênicos, o ácido cafeoilquínico (CQA) e seus isômeros (3-CQA, 4-CQA e 5-CQA). Essas substâncias representam, segundo Toci et al. (2006) e Perrone et al. (2008), de $76 \%$ a $84 \%$ do total de ACGs presentes no café. Nas Tabelas 3 e 4 estão indicadas as quantificações dos ACGs.

Tabela 2. Resultados da validação com CLAE de ACSs e açúcares (sacarose, frutose e glucose).

\begin{tabular}{|c|c|c|}
\hline Parâmetro de Validação & Analitos & Resultados \\
\hline \multirow{4}{*}{ Linearidade $(\mu \mathrm{g} / \mathrm{mL}) / \mathrm{R}^{2}$} & ACSs-5 CQA & $0,2-50 / 0,9998$ \\
\hline & Sacarose & 0.25-30 $\mu \mathrm{g}$ em $20 \mu \mathrm{L} / 0,9993$ \\
\hline & Glucose & $0.25-30 \mu \mathrm{g}$ em $20 \mu \mathrm{L} / 0,9993$ \\
\hline & Frutose & 0.25-30 $\mu \mathrm{g}$ em $20 \mu \mathrm{L} / 0,9995$ \\
\hline \multirow{4}{*}{$\begin{array}{l}\text { Limite de detecção e quantificação do } \\
\text { equipamento-LDE/LDQE }(\mu \mathrm{g} / \mathrm{mL})\end{array}$} & ACSs-5 CQA & $0,05 / 0,20$ \\
\hline & Sacarose & 0,20/0,40 em $20 \mu \mathrm{L}$ \\
\hline & Glucose & 0,20/0,40 em $20 \mu \mathrm{L}$ \\
\hline & Frutose & 0,20/0,40 em $20 \mu \mathrm{L}$ \\
\hline \multirow{4}{*}{$\begin{array}{l}\text { Limite de detecção e quantificação dos } \\
\text { métodos-LDM/LDQM }(\mu \mathrm{g} / \mathrm{mL})\end{array}$} & ACSs-5 CQA & $0,053 / 0,214$ \\
\hline & Sacarose & $0,23 / 0,45$ em $20 \mu \mathrm{L}$ \\
\hline & Glucose & $0,23 / 0,45$ em $20 \mu \mathrm{L}$ \\
\hline & Frutose & $0,23 / 0,45$ em $20 \mu \mathrm{L}$ \\
\hline \multirow{4}{*}{$\begin{array}{c}\text { Exatidão- Porcentagem de recuperação } \\
\text { (\%)-Diferentes concentrações em } \\
\text { triplicatas }\end{array}$} & ACSs-5 CQA & $78-114$ \\
\hline & Sacarose & $74-99$ \\
\hline & Glucose & $103-130$ \\
\hline & Frutose & $100-128$ \\
\hline
\end{tabular}

CLAE - Cromatografia líquida de alta eficiência; ACSs - Ácidos clorogênicos; 5-CQA - 5 acido cafeoilquinico; LDE - Limite de detecção do equipamento; LDQE - Limite de quantificação do equipamento.

Tabela 3. Concentrações médias em (\%) de 5-CQA para os três diferentes lotes de cafés, durante o monitoramento das etapas pós-colheita.

\begin{tabular}{cllc}
\hline ETAPAS & LOTE 1 (L1) & LOTE 2 (L2) & LOTE 3 (L3) \\
\hline Terreiro 1 (T1) & $2,43 \pm 0,01 \mathrm{~dB}$ & $3,43 \pm 0,09 \mathrm{cA}$ & $3,14 \pm 0,03 \mathrm{cA}$ \\
Terreiro 2 (T2) & $3,16 \pm 0,05 \mathrm{cA}$ & $3,34 \pm 0,09 \mathrm{cA}$ & $3,92 \pm 0,01 \mathrm{~b} \mathbf{A}$ \\
Terreiro 3 (T3) & $2,62 \pm 0,02 \mathrm{~d} \mathbf{C}$ & $3,20 \pm 0,09 \mathrm{cB}$ & $4,35 \pm 0,07 \mathrm{ab} \mathbf{A}$ \\
Terreiro 4 (T4) & $3,99 \pm 0,09 \mathrm{~b}$ & $3,84 \pm 0,02 \mathrm{bc}$ & $\mathrm{NA}$ \\
Após Secador & $4,66 \pm 0,09 \mathrm{aA}$ & $3,60 \pm 0,09 \mathrm{cB}$ & $4,31 \pm 0,01 \mathrm{ab} \mathbf{A}$ \\
Meio da Tulha & $4,52 \pm 0,08 \mathrm{aB}$ & $5,02 \pm 0,07 \mathrm{aA}$ & $4,07 \pm 0,01 \mathrm{ab} \mathbf{C}$ \\
Final da Tulha & $4,65 \pm 0,03 \mathrm{aA}$ & $4,48 \pm 0,09 \mathrm{ab} \mathbf{A}$ & $4,38 \pm 0,09 \mathrm{aA}$ \\
Final do Armazenamento & $4,73 \pm 0,03 \mathrm{aAB}$ & $5,15 \pm 0,09 \mathrm{aA}$ & $4,42 \pm 0,08 \mathrm{aB}$ \\
Torrado & $1,68 \pm 0,04 \mathrm{eA}$ & $1,07 \pm 0,04 \mathrm{~d} \mathbf{B}$ & $1,12 \pm 0,03 \mathrm{~dB}$ \\
Bebida & $0,70 \pm 0,01 \mathrm{fA}$ & $0,65 \pm 0,07 \mathrm{~d} \mathbf{B}$ & $0,62 \pm 0,01 \mathrm{eBC}$ \\
\hline
\end{tabular}

Médias seguidas por letras minúsculas diferentes na mesma coluna e letras maiúsculas em negrito na mesma linha, correspondem a diferença significativa entre as etapas do processamento e entre os lotes, respectivamente, a $(p<0,05)$.

*Não analisado (O Lote 3 não precisou da etapa T4). 
Tabela 4. Concentrações médias dos ácidos clorogênicos 3-CQA e 4-CQA para os três diferentes lotes de cafés, durante o monitoramento das etapas pós-colheita.

\begin{tabular}{|c|c|c|c|c|c|c|}
\hline \multirow{2}{*}{ Etapas } & 1) & LOTE 2 (L2) & 3) & E 1 (L1) & LOTE 2 (L2) & E 3 (L3) \\
\hline & \multicolumn{3}{|c|}{ 3-CQA (\%) } & \multicolumn{3}{|c|}{ 4-CQA (\%) } \\
\hline Terreiro 1 (T1) & $0,01 \mathrm{fC}$ & $0,45 \pm 0,01 \mathrm{ed} \mathbf{B}$ & $, 51 \pm 0,02$ eA & 38 & $0,58 \pm 0,01 d c \mathbf{A}$ & $0,03 \mathrm{e} \mathbf{A}$ \\
\hline Terreiro 2 (T2) & $48 \pm 0,05$ deB & $, 36 \pm 0,02$ eC & $0,60 \pm 0,05 \mathrm{~cd} \mathbf{A}$ & 0,01 fB & $0,42 \pm 0,02$ eC & $0,70 \pm 0,03 \operatorname{ced} \mathbf{A}$ \\
\hline Terreiro 3 (T3) & eC & $0,45 \pm 0,02$ edB & $67 \pm 0,04 \mathrm{cb} \mathbf{A}$ & gC & $0,51 \pm 0,07 \mathrm{de} \mathbf{B}$ & $0,77 \pm 0,01 \mathrm{cb} \mathbf{A}$ \\
\hline Terrei & dc & $55 \pm 0,0$ & NA & c & c & NA \\
\hline Após & $\mathrm{CA}$ & $56 \pm 0,0$ & $8 \pm 0,0$ & $\mathrm{eA}$ & $0,61 \pm 0, c$ & $\mathrm{cb} \mathbf{A}$ \\
\hline Meio & & $69 \pm 0,0$ & & & $0,80 \pm 0,0$ & $\mathrm{cbd} \mathbf{A}$ \\
\hline Final da Tulha & $65 \pm 0,02 \mathrm{cA}$ & $0,64 \pm 0,01 \mathrm{cb} \mathbf{A}$ & $0,68 \pm 0,03 \mathrm{~b} \mathbf{A}$ & $0,74 \pm 0,01 d c \mathbf{A}$ & $0,77 \pm 0,01 \mathrm{~b} \mathbf{A}$ & $0,80 \pm 0,03 \mathrm{cb} \mathbf{A}$ \\
\hline $\begin{array}{c}\text { Final do } \\
\text { Armazenamento }\end{array}$ & A & $1 \mathrm{~b} \mathbf{A}$ & $0,02 \mathrm{cb} \mathbf{A}$ & deA & $0,08 \mathrm{~b} \mathbf{A}$ & A \\
\hline Torrado & $88 \pm 0,02$ b $\mathbf{A}$ & $0,57 \pm 0,13 \mathrm{cB}$ & $0,55 \pm 0,01 \mathrm{ed} \mathbf{B}$ & $0,96 \pm 0,01 \mathrm{~b} \mathbf{A}$ & $0,62 \pm 0,02 d c \mathbf{B}$ & $0,66 \pm 0,02 \mathrm{ed} \mathbf{B}$ \\
\hline Bebida & $1,07 \pm 0,03$ a $\mathbf{A}$ & $0,96 \pm 0,06 \mathrm{aB}$ & $0,92 \pm 0,06 \mathrm{aC}$ & $1,22 \pm 0,05 \mathrm{a} \mathbf{A}$ & $1,12 \pm 0,03 \mathrm{aB}$ & $1,08 \pm 0,01 \mathrm{aC}$ \\
\hline
\end{tabular}

Médias seguidas por letras minúsculas diferentes na mesma coluna e letras maiúsculas em negrito na mesma linha, correspondem à diferença significativa entre as etapas do processamento e entre os lotes, respectivamente, a $(p<0,05)$.

As porcentagens correspondentes ao total dosACGs nas amostras de café cru, referentes às etapas finais de processamento, estavam de acordo com a faixa de valores citadas na literatura (KY et al., 2001; FARAH et al., 2005; PIMENTA; VILELA, 2002; PIMENTA; VILELA, 2006; RAMALAKSHMI et al., 2007; PUERTA, 2011). Esses valores podem representar de 5 a $8 \%$, e de 7 a 11\% nas espécies Coffeea arábica e C. canephora, respectivamente. Pérez-Hernández et al. (2013) encontraram de 90 a 174 mg/g de ACGs em grãos crus de cafés robusta e arábica, respectivamente. No mesmo estudo, reportou-se um aumento de ACGs em café robusta cru após a torração com relação ao café robusta sem torrar, devido à concentração de componentes solúveis.

\subsection{5-CQA}

O resultado dos valores médios do teor de 5-CQA, durante as etapas de processamento pós-colheita do café, foram avaliados nos três diferentes estádios de maturação (L1, L2, L3) e foram expressos na Tabela 3.

Observou-se que houve diferença significativa no teor de 5-CQA no lote L1 nas etapas iniciais do processamento (T1 a T4); por outro lado, as etapas finais não diferiram significativamente entre si $(p<0,05)$. Para o lote L2, não houve diferença significativa nas etapas inicias; porém, a partir da etapa T4, algumas etapas apresentaram diferenças importantes. Para o lote L3, somente a etapa T1 diferiu das demais. De um modo geral,tanto o café torrado quanto a bebida diferiram significativamente das demais etapas, em todos os três lotes.

Com relação aos teores de 5-CQA quantificados em grãos crus, os mesmos estavam acima dos valores citados por Farah et al. (2005), que encontraram 3,12\% de 5-CQA em grãos crus de café arábica e cultivar Bourbon.
De acordo com Toci et al. (2006), os autores relataram concentrações de 3,98\% em grãos crus; no entanto, Perrone et al. (2008) encontraram teores de 6,67\%, para café arábica. Puerta (2011) reportou valores de ácidos clorogênicos para café maduro arábico colombiano com valores de $5,24 \%$ a $7,61 \%$, e para café robusta, valores de $7,45 \%$ a $10,59 \%$. Diferenças observadas nas concentrações de 5-CQA indicadas por diferentes autores, podem ter ocorrido em função das variedades, das diferentes condições climáticas e do tipo de processamento ao qual foram submetidos os cafés estudados.

Também na Tabela 3, observou-se que os três lotes diferiram significativamente entre si para a maioria das etapas estudadas, e o lote que apresentou maior concentração de 5-CQA foi o L2, no qual $100 \%$ dos frutos foram cereja. De acordo com a literatura, amostras contendo frutos crus e pretos apresentaram concentrações de ACGs totais mais elevadas, no entanto Marin e Puerta (2008) indicaram que ocasionalmenteestas relações mantêm esta tendência.

De fato, o teor de 5-CQA aumentou ao longo do processamento pós-colheita para os três lotes, apesar de apresentarem diminuições em algumas etapas. A maior diminuição no teor desta variável ocorreu após a torração, com menor concentração na bebida. Segundo Farah et al. (2005), a diminuição que ocorre no teor de 5-CQA deve-se a inúmeras reações que podem ocorrer durante a torração, tais como: isomerização, hidrólise, oxidação, fragmentação, polimerização e associação com proteínas desnaturadas. Logo, a alta temperatura durante o processo de torração causa a quebra do carbono vinculado ao ACG, resultando em isomerização e degradação da molécula. Verificou-se também que depois de cinco minutos de torração, o nível de 5-CQA diminuiu substancialmente, cerca de $60 \%$. 


\subsection{Isômeros 3 e 4-CQA}

Os resultados dos valores médios dos teores dos isômeros 3 e 4-CQA durante as etapas de processamento pós-colheita dos cafés avaliados, nos três diferentes estádios de maturação (Lote 1, Lote 2 e Lote 3), foram exibidos na Tabela 4.

Ambos isômeros apresentaram comportamento similar, contudo observou-se que o lote L1 mostrou uma instabilidade nos teores destes isômeros, ora com valores maiores, ora menores, durante as etapas do processamento. Para os lotes L1 e L2, as primeiras etapas de secagem apresentaram diferenças significativas entre si ( $p \leq 0,05 \%)$, e a partir da etapa Terreiro 4, as amostras dos grãos crus não indicaram diferenças significativas. Para o lote L3, verificou-se maior estabilidade nesta variável analisada, na qual somente a etapa Terreiro 1 diferiu significativamente das demais.

Avaliando a existência de diferenças significativas entre os estádios de maturação estudados, observou-se que os três estádios (L1, L2 e L3) apresentaram estas diferenças somente nas etapas de secagem natural em terreiro; no entanto, finalizado o processo de secagem, os lotes não diferiram mais.

Com relação à variação ocorrida com os isômeros 3-CQA e 4-CQA durante o processamento do café, foi possível verificar que ambos mostraram comportamentos semelhantes, sendo observado um pequeno aumento em suas concentrações durante a pós-colheita, primeiramente após a torração e por fim na bebida.

Autores como Trugo e Macrae (1984) e Farah e Donangelo (2006) explicaram em seus trabalhos que o aumento desses isômeros pode ocorrer em função da decomposição do isômero 5-CQA em 3 e 4-CQA por inúmeras reações químicas ocorridasdurante a torração.

Sabe-se que a qualidade sensorial da bebida está inversamente relacionada com a quantidade dos ACGs presentes nos grãos. Segundo Puerta (2011), o conteúdo dos ácidos clorogênicos em uma xícara de café depende de alguns parâmetros, tais como: espécie, grau de maturação do grão, processamento e grau de torração, em que há menor quantidade no café descafeinado. Deste modo, este componente é importante para o desenvolvimento do sabor durante a torração, e também tem forte influência sobre a adstringência da bebida,o amargor, acidez e limpeza do sabor (RIBEIRO et al., 2011). Mesmo em baixas concentrações, os ACGs possuem impacto na qualidade da bebida.

\subsection{Sacarose}

Os resultados dos valores médios do teor de sacarose durante as etapas de processamento pós-colheita dos cafés avaliados nos três diferentes estádios de maturação Lote 1, Lote 2 e Lote 3 estão ilustrados na Figura 2a.
Ao longo do processamento, os lotes 1 e 2 apresentaram comportamentos semelhantes, sendo que as etapas T1, T2 e T3 não diferiram entre si, mas diferenciaram-se significativamente $(p<0,05)$ em todas as outras etapas. Verificou-se também que, após a secagem em secador rotativo, não houve diferença significativa nas demais etapas para os lotes 1 e 2. Com relação ao lote 3 , apenas a primeira etapa ( $\mathrm{T} 1)$ diferiu das demais. Em todos os três lotes, houve diferença entre grãos crus e grãos torrados.

Na Figura 2a, observou-se em L1 e L2 a maior variação na concentração dos açúcares nos grãos que ocorreu durante a secagem dos mesmos em terreiro. Villela (2002) avaliou açúcares em cafés naturais durante o processo de secagem, e também verificou uma grande variação no teor deste componente durante as primeiras 72 horas de secagem. Com base nestes dados, pôde-se destacar mais uma vez a importância da demanda de cuidados durante a secagem dos frutos em terreiro.Devido ao alto teor de umidade das sementes, existem condições propícias para a ocorrência de eventos bioquímicos capazes de alterar a composição química do café, desta maneira alterando sua qualidade final.

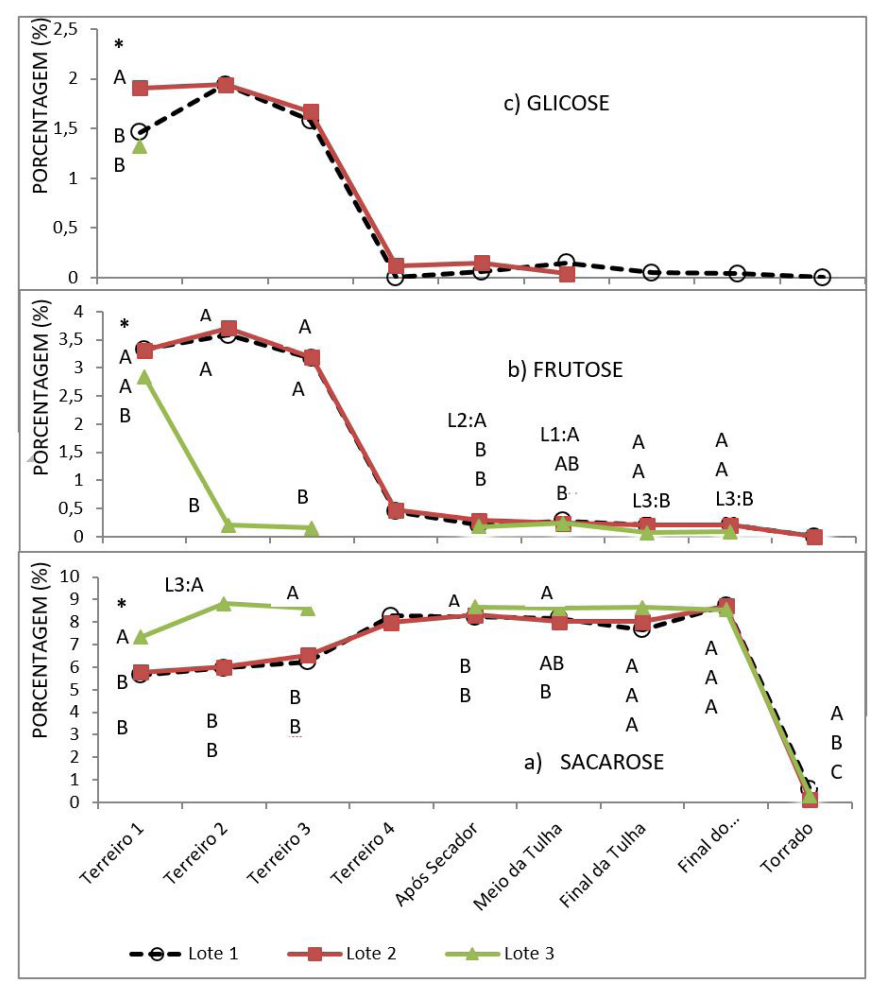

Figura 2. Variação no teor (\%) de a) sacarose, b) frutose e c) glicose durante as etapas do processamento, para os três lotes (Lote 1, Lote 2, Lote 3), colhidos em diferentes estádios de maturação. *Médias seguidas por letra maiúscula, correspondem à diferença significativa entre as etapas do processamento e entre os lotes, respectivamente, a $(p \leq 0,05)$. 
Os teores de sacarose encontrados para os grãos crus apontaram um aumento de 56\% no início do processamento, Terreiro1 (5,65\%), e no final do armazenamento $8,74 \%$. Estes valores estão próximos aos encontrados por diferentes autores, que reportaram valores entre 4,6\% e 9,65\% para grãos crus ( $\mathrm{TOCl}$ et al., 2006; MURKOVIC; DERLER, 2006; ALCÁZAR et al., 2005; KNOPP et al., 2005).

Com relação às diferenças existentes entre os estádios de maturação (L1, L2, L3), observou-se que os lotes 1 e 2 não diferiram significativamente entre si, porém houve diferença no lote 3 durante as etapas de secagens natural e artificial.

O lote 3 apresentou um comportamento semelhante referente à variação do teor de açúcar entre as etapas, porém exibiu um alto teor de sacarose no início do processo, que se mantevedurante todo o processamento. Tal fato pode ser explicado pela colheita tardia dos frutos, que foi realizada 45 dias após a primeira colheita. Segundo Rogers et al. (1999), Redgwell e Fischer (2006), o teor de sacarose nas sementes tende a aumentar conforme a maturação dos grãos. Logo, quanto mais maduro, maior o teor de sacarose; e sendo assim, os resultados sugeriram que seria uma vantagemo grão de café amadurecer e secar na árvore.

Os valores encontrados para o teor de sacarose em grãos torrados variaram de $0,12 \%$ a $0,59 \%$. Estes valores estão de acordo com os valores encontrados por Toci et al. (2006), que encontraram concentrações de $0,70 \%$ para grão de torra clara.

Segundo trabalhos de Fernandes et al. (2003) e Pinto et al. (2002), a acentuada diminuição nos teores de sacarose entre os grãos cru e torrado pode ser explicada pela decomposição da sacarose em glicose e frutose, que ocorre após a hidrólise durante o processo de torração.

\subsection{Frutose e glicose}

Ao longo do processamento, os valores médios dos teores de frutose (Figura 2b) e glicose (Figura 2c) nos grãos dos lotes 1 e 2 apresentaram comportamentos semelhantes, sendo que as etapas T1, T2 e T3 e T4 diferiram significativamente $(p<0,05)$ de todas as outras etapas. Após a secagem, não houve diferença significativa entre esta etapa e as demais para os lotes 1 e 2. Parao lote 3 , apenas a primeira etapa (T1) diferiu das demais, e nestelote também não foram detectadas concentrações de glicose nos grãos após a etapa T1.

Redgwell e Fischer (2006) relataram em seus estudos que desde os primeiros estágios de desenvolvimento do fruto até a metade do estágio de maturação, os açúcares glicose e frutose estiveram presentes em maior concentração, sendo que a glicose possuiu o dobro da concentração da frutose. Com base nos níveis de glicose, altos níveis encontrados na variedade arábica variaram de $8 \%$ a $12 \%$ em massa seca, ao passo que na variedade robusta houve variação de $2 \%$ a $4 \%$. No final do desenvolvimento dos frutos, as concentrações de glicose e frutose diminuíram em ambas espécies de 0,03\% para 0,04\% em massa seca, respectivamente. No fruto maduro, o decréscimo dos açúcares redutores foi acompanhado pelo acréscimo da sacarose.

Os teores de frutose encontrados para os grãos crus que representaram a última etapa do processamento (Final do Armazenamento) variaram de 0,09\% a 0,21\% nos três lotes analisados. Murkovic e Derler (2006) encontraram valores médios de 0,14\% em grãos crus do café arábica, e de valores não detectados a 0,19\% (KNOPP et al., 2005).

Para os lotes 1 e 2, as concentrações iniciais de frutose e glicose foram relativamente altas e sofreram uma brusca diminuição após a etapa T4. Este fato pode ser explicado pela presença da mucilagem nos grãos que representavam as amostras coletadas nas etapas T1, T2, T3. Os frutos amostrados nestas etapas foramdespolpados manualmente em laboratório para a realização das análises, enquanto os frutos a partir da etapa T4 tiveram a casca e a membrana que os envolviamretiradas pela máquina beneficiadora.

Por fim, os teores de glicose encontrados nos grãos crus representaram as últimas etapas do processamento, nos quais as concentrações foram muito pequenas ou não detectadas. Estes valores estavam abaixo dos valores encontrados por outros autores, com dados entre 0,14\% e 0,22\% (MURKOVIC; DERLER, 2006).

No caso do lote 3, todas as amostras subsequentes à etapa Terreiro 1 também foram beneficiadas para a realização das análises, devido à dificuldade do despolpamento manual destes frutos, queforam retirados muito secos da árvore.

Villela (2002) avaliou em seu trabalho a qualidade do café despolpado, desmucilado, descascado e natural, durante o processo de secagem, e este autor também observou que o café despolpado apresentou um menor valor para os açúcares redutores, possivelmente pela retirada da mucilagem durante o processamento destes grãos. Knopp et al. (2005) estudaram os teores de açúcares em cafés arábica submetidos a três diferentes tipos de processamento, e encontraram teores médios de frutose e glicose de 0,33\% e 0,30\%, respectivamente, para frutos processados por via seca; em contrapartida, pela via úmida encontraram valores de 0,05\% e 0,03\% para frutose e glicose, respectivamente. Este estudo confirmaria a hipótese de que a marcante diminuição no teor da frutose nas etapas iniciais (T1, T2, T3) quando comparada as demais etapas, estaria relacionada à presença da mucilagem nos grãos analisados nas etapas iniciais de secagem para os lotes 1 e 2 . 
Análises de açúcares e ácidos clorogênicos de cafés colhidos em diferentes estádios de maturação e após o processamento Santos, R. A. et al.

Com relação às diferenças existentes nos estádios de maturação ( $L 1, L 2, L 3)$, observou-se também nas Figuras 2b e c, para frutose e glicose, que os lotes 1 e 2 não diferiram significativamente entre si, porém diferenciaram-se do lote 3 em quase todas as etapas.

Com referência aos grãos torrados nos três lotes avaliados, não foram detectadas a frutose e glicose. Logo, a ausência de frutose e glucose, oumesmo baixas concentrações encontradas em grãos torrados, podem ocorrer em função da participação destes acúcares nas reações de Maillard com o grupo amino durante o processo de torração.

\section{Conclusão}

Os resultados obtidos sugeriram que o lote 3 (graõs colhidos tardiamente) apresentou a menor concentração de ACSs em todo o processamento, incluindo a torração e a bebida. Além disto, no L3 encontrou-se maior concentração de sacarose. Nas condições realizadas deste estudo, mostrou-se que uma boa alternativa de procedimento seriao grão de café secar na árvore, pois pode trazer benefícios à qualidade da bebida de café. No entanto, cabe ressaltar que, embora os resultados dos componentes analisados tenham apresentado diferenças significativas nos lotes, as diferenças quantitativas foram mínimas. Verificou-se que o teor de sacaroseaumentou durante o processamento, enquanto os teores de frutose e glicose apresentaram diminuição. As alterações mais proeminentes, com relação ao teor de sacarose, ocorreram durante as etapas de secagem em terreiro; porém, nas etapas subsequentes as alterações foram menores. Após a torração, os níveis de sacarose diminuíram bastante, e não foram encontrados os açúcares glicose e frutose nos grãos torrados. Para os três açúcares estudados, os lotes 1 e 2 apresentaram comportamento muito semelhante no processamento pós-colheita.

\section{Referências}

ALCÁZAR, A.; JURADO, J. M.; MARTÍN, M. J.; PABLOS, F.; GONZALÉS, G. Enzymatic-spectrophotometric determination of sucrose in coffee beans. Talanta, v. 67, n. 4, p. 760-766, 2005. http://dx.doi.org/10.1016/j.talanta.2005.04.005. PMid:18970237.

ARRUDA, N. P.; HOVELL, A. M. C.; REZENDE, C. M.; FREITAS, S. P.; COURI, S.; BIZZO, H. R. Correlação entre precursores e voláteis em café arábica brasileiro processado pelas vias seca, semiúmida e úmida e discriminação através da análise por componentes principais. Quimica Nova, v. 35, n. 10, p. 20442051, 2012. http://dx.doi.org/10.1590/S0100-40422012001000026.

CHIRINOS, R.; CAMPOS, D.; COSTA, N.; ARBIZU, C.; PEDRESCHI, R.; LORANDELLE, Y. Phenolic profiles of andean mashua (Tropaeolum tuberosum Ruíz \& Pavón) tubers: Identification by HPLC-DAD and evaluation of their antioxidant activity. Food
Chemistry, v. 106, n. 3, p. 1285-1298, 2008. http://dx.doi. org/10.1016/j.foodchem.2007.07.024.

CLIFFORD, M. N. Chorogenic acids and other cinnamates nature, occurence and dietary burden. Journal of Food \& Agriculture, v. 79, n. 3, p. 362-372, 1999. http://dx.doi.org/10.1002/(SICI)10970010(19990301)79:3<362::AID-JSFA256>3.0.CO;2-D.

FARAH, A.; DONANGELO, C. M. Phenolic compounds in coffee. Brazilian Journal of Plant Physiology, v. 18, n. 1, p. 124-138, 2006. http://dx.doi.org/10.1590/S1677-04202006000100003.

FARAH, A.; PAULIS, T.; TRUGO, L. C.; MARTIN, P. R. Effect of roasting on the formation of chlorogenic acid lactones in coffee. Journal of Agricultural and Food Chemistry, v. 53, n. 5, p. 15051513, 2005. http://dx.doi.org/10.1021/jf048701t. PMid:15740032.

FERNANDES, S. M.; PEREIRA, R. G. A. F.; LOPES, L. M. V.; NERY, F. C. Teores de açúcares dos cafés torrados e moídos armazenados em diferentes condições de ambiente. Revista Brasileira de Armazenamento, n. 7, p. 108-113, 2003.

ILLY, A.; VIANI, R. Espresso coffee - the chemistry of quality. 3rd ed. London: Academic Press Limited, 1998. 235 p.

KNOPP, S.; BYTOF, G.; SELMAR, D. Influence of processing on the content of sugars in green Arabica coffee beans. European Food Research and Technology, v. 223, n. 2, p. 195-201, 2005. http://dx.doi.org/10.1007/s00217-005-0172-1.

KY, C.-L.; LOUARN, J.; DUSSERT, S.; GUYOT, B.; HAMON, S.; NOIROT, M. Caffeine, trigonelline, chlorogenic acids and sucrose diversity in wild Coffea arabica L. and C. canephora P. accessions. Food Chemistry, v. 75, n. 2, p. 223-230, 2001. http://dx.doi.org/10.1016/S0308-8146(01)00204-7.

MARIA, C. A. B.; MOREIRA, R. F. A. Métodos para análise de ácido clorogênico. Quimica Nova, v. 27, n. 4, p. 586-592, 2004.

MARIN, C.; PUERTA, G. Contenido de ácidos clorogénicos en granos de Coffea Arabica y C. Canephora, según el desarrollo del fruto. Cenicafe, v. 59, n. 1, p. 7-28, 2008.

MURKOVIC, M.; DERLER, K. Analysis of amino acids and carbohydrates in green coffee. Journal of Biochemical and Biophysical Methods, v. 69, n. 1-2, p. 25-32, 2006. http://dx.doi. org/10.1016/j.jbbm.2006.02.001. PMid:16563515.

PÉREZ-HERNÁNDEZ, L. M.; CHÁVEZ-QUIROZ, K.; MEDINAJUÁREZ, L. Á.; MEZA, N. G. Compuestos fenólicos, melanoidinas y actividad antioxidante de café crú y porcesdo de las especies Coffea arabica y Coffea canephora. Biotecnia, v. 15, n. 1, p. 51-56, 2013. http://dx.doi.org/10.18633/bt.v15i1.136.

PERRONE, D.; FARAH, A.; DONANGELO, C. M.; PAULIS, T.; MARTIN, P. R. Comprehensive analysis of major and minor chlorogenic acids and lactones in economically relevant Brazilian coffe cultivars. Food Chemistry, v. 106, n. 2, p. 859-867, 2008. http://dx.doi.org/10.1016/j.foodchem.2007.06.053. 
Análises de açúcares e ácidos clorogênicos de cafés colhidos em diferentes estádios de maturação e após o processamento Santos, R. A. et al.

PIMENTA, C. J.; VILELA, E. R. Qualidade do café (Coffea arabica L.) colhido em sete épocas diferentes na região de Lavras-MG. Ciência e Agrotecnologia, p. 1481-1491, 2002. Edição Especial.

PIMENTA, C. J.; VILELA, E. R. Compostos fenólicos e qualidade da bebida. Coffee Break, 2006. Disponível em: <http://www. coffeebreaak.com.br/ocafezal.asp>. Acesso em: 1 jun. 2007.

PINTO, N. A. V. D.; PERREIRA, R. G. F. A.; FERNANDES, S. M.; THÉ, P. M. P.; CARVALHO, V. D. Caracterização dos teores de polifenóis e açúcares em padrões de bebida do café (Coffea arabica L.) cru e torrado do sul de Minas Gerais. Revista Brasileira de Armazenamento, n. 4, p. 52-58, 2002. Especial Café.

PUERTA, G. Composición de uma taza de café. Avances em Química, n. 414, p. 1-12, 2011.

QUATROCCHI, O. A.; ANDRIZZI, S. A.; LABA, R. F. Validación de métodos. In: QUATROCCHI, O. A.; ANDRIZZI, S. A.; LABA, R. F. Introducción a la HPLC: aplicación y prática. Buenos Aires: Artes Gráficas Farro, 1992. cap. 12, p. 301-328.

RAMALAKSHMI, K.; KUBRA, I. R.; RAO, L. J. M. Physicochemical characteristics of green coffee: comparasion of graded and defactive beans. Journal of Food Science, v. 72, n. 5, p. 333-336, 2007. http://dx.doi.org/10.1111/j.1750-3841.2007.00379.x. PMid:17995751.

REDGWELL, R.; FISCHER, M. Coffee carbohydrates. Brazilian Journal of Plant Physiology, v. 18, n. 1, p. 165-174, 2006. http:// dx.doi.org/10.1590/S1677-04202006000100012.

RIBEIRO, J.S.; FERREIRA, M.; SALVA, T. Chemometric models for the quantitative descriptive sensory analysis of Arabica coffee beverages using near infrared spectroscopy. Talanta, v. 83, n. 5, p. 1352-1358, 2011. http://dx.doi.org/10.1016/j. talanta.2010.11.001. PMid:21238720.

ROGERS, W. J.; MICHAUX, S.; BASTIN, M.; BUCHELI, P. Changes tothe content of sugars, sugar alcohols, myo-inositol, carboxylicacids, and inorganic anions in developing grains from differentvarieties of robusta (Coffea canephora) and Arabica ( $C$. arabica L.) coffees. Plant Science, v. 149, n. 2, p. 115-123, 1999. http://dx.doi.org/10.1016/S0168-9452(99)00147-8.

TAVARES, L. A.; FERREIRA, A. G. Análises quali e quantitativa de cafés comercias via ressonância magnética nuclear. Revista Química Nova, v. 29, n. 5, p. 911-915, 2006. http://dx.doi. org/10.1590/S0100-40422006000500005.

TOCI, A.; TRUGO, L. C.; FARAH, A. Efeitos do processo de descafeinação com Diclorometano sobre a composição química dos cafés arábica e robusta antes e após a torração. Revista Química Nova, v. 29, n. 5, p. 965-971, 2006. http://dx.doi. org/10.1590/S0100-40422006000500015.

TRUGO, L. C.; MACRAE, R. Chlorogenic acid composition of instant coffee. The Analyst, v. 109, n. 3, p. 263-266, 1984. http:// dx.doi.org/10.1039/an9840900263. PMid:6721155.

VIGNOLI, J.; BASSOLI, D.; BENASSI, M. Antioxidant activity, polyphenols, caffeine and melanoidins in soluble coffee: The influence of processing conditions and raw material. Food Chemistry, v. 124, n. 3, p. 863-868, 2011. http://dx.doi. org/10.1016/j.foodchem.2010.07.008.

VILLELA, T. C. Qualidade do café despolpado, desmucilado, descascado e natural, durante o processo de secagem. 2002. 69 f. Dissertação (Mestrado em Ciência dos Alimentos), Universidade Federal de Lavras, Lavras, 2002. 